\title{
ENERGIZE SUA ESCOLA: UM PROJETO DE EXTENSÃO PARA ADEQUAR ÀS INSTALAÇÕES ELÉTRICAS ESCOLARES
}

DOI: 10.37702/2175-957X.COBENGE.2021.3437

Franciele Peruchi Ronchi - franperuchi@hotmail.com

Centro universitário UNISATC

BELO MONTE 55

88809-275 - CRICIÚMA - SC

André Abelardo Tavares - andre.tavares@satc.edu.br

Centro universitário UNISATC

Pascoal Meller 83

88809-330 - Criciúma - SC

Marcos Antonio Martins Giassi - marcosgiassi7@gmail.com

Centro universitário UNISATC

Meleiro, SC S/N

88920-000 - Meleiro - SC

Ivan Meneghel Freitas - ivan_meneghel@hotmail.com

Centro universitário UNISATC

Rua Juliana Potrikus Stacovsk 88

88813-813 - Criciúma - SC

Victor Matheus Augustinho Raupp - victor.raupp@outlook.com

Centro universitário UNISATC

Rua São Martinho 387

88805-415 - Criciúma - SC

Resumo: Os projetos de extensão quando desenvolvidos de maneira adequada, causam grande impacto na sociedade e na formação dos alunos e professores engajados no mesmo. Este artigo apresenta etapas de desenvolvimento, e os principais resultados obtidos no âmbito social e acadêmico do projeto intitulado "Energize sua Escola". Uma característica ímpar deste projeto é a interação entre os diferentes níveis de ensino, neste caso, acadêmicos do curso de Engenharia Elétrica e alunos do curso de técnico de eletrotécnica da instituição de ensino da SATC. Apresenta ainda, a relação das disciplinas do curso com o que é 


\section{(C. COBENGE e IV Simpósio Internacional

desenvolvido neste projeto de extensão. Por fim, é apresentado o feedback do ponto de vista dos alunos que participaram deste projeto da escola municipal de Criciúma, E. M. E. I. E. F Santa Rita de Cássia no ano de 2018.

Palavras-chave: Educação, Extensão, Trabalho Social, Eletricidade. 


\section{ENERGIZE SUA ESCOLA: UM PROJETO DE EXTENSÃO PARA ADEQUAR ÀS INSTALAÇÕES ELÉTRICAS DE ESCOLAS}

INTRODUÇÃO

O uso da energia elétrica vem crescendo com o decorrer dos anos, tanto no meio industrial e comercial, como no meio residencial. No âmbito residencial o crescimento da demanda de energia está relacionado com a inserção de equipamentos de refrigeração e novas tecnologias que possibilitam uma melhor qualidade de vida.

Todas as edificações estão sujeitas ao desgaste natural decorrente do tempo, assim também ocorre com as instalações elétricas. Este desgaste natural juntamente ao aumento da carga na rede elétrica e com a não observância das normas, causam mau funcionamento e aumentam as ocorrências de choques elétricos e incêndios provocadas por sobrecargas (FREITAS, 2010).

Para garantir o correto funcionamento das instalações elétricas e prevenção de acidentes, todos os trabalhos desta área, seja em projetos, execução e outros, devem seguir as recomendações das normas básicas como a ABNT NBR 5410 - 2004 (para baixa tensão em geral), a NR-10 - 2004 (para segurança em instalações e serviços em eletricidade), a ABNT NBR 5419 - 2015 (proteção de estruturas contra descargas atmosféricas), a ABNT NBR 14039 - 2005 (para média tensão), entre outras (FREITAS, 2010).

O projeto de extensão busca fazer a aproximação do aluno com a sociedade, contribuindo na formação integral do estudante, estimulando sua formação como cidadão crítico e responsável. A concepção da extensão tem relação com a comunidade geral, em que o aluno coloca em prática aquilo que foi aprendido em sala de aula e desenvolve fora dela, pondo em contato o aprendiz com a sociedade gerando benefícios para ambos os lados (ANDRADE; INCROCCI, 2018; ARAÚJO FILHO; THIOLLENT, 2008).

Este artigo trata do Projeto de Extensão, desenvolvido na Instituição de Ensino SATC, que auxilia na avaliação e revitalização das instalações elétricas das escolas municipais da cidade de Criciúma/SC. Este projeto tem o envolvimento dos alunos da graduação em Engenharia Elétrica e do ensino técnico em Eletrotécnica e tem como objetivo a integração do ambiente acadêmico com a comunidade local visando o descobrimento de novas habilidades e aproximação de um ambiente de trabalho, aplicando os conhecimentos teóricos na prática e contribuindo para a produção de um ambiente de estudo de qualidade e um aumento no rendimento escolar do aluno.

\section{PROJETO DE EXTENSÃO}

As primeiras ocorrências de extensão no Brasil se deram entre 1911 e 1917, na Universidade Livre de São Paulo, através de conferências. Em 1987 em Brasília foi criado o Fórum Nacional de Pró-Reitores de Extensão das Universidades públicas Brasileiras (PROEXT). Entre 1999 e 2001 A Lei de Diretrizes e Bases da Educação Nacional (LDBEN - Lei9394/96) e o Plano Nacional de Extensão reorganizam a questão da indissociabilidade das atividades de ensino, pesquisa e extensão, fazendo com que as IES repensem sua função social colocando em regularização a natureza da finalidade de suas atividades (CARBONARI; PEREIRA, 2007). 
Muitos são os projetos de extensão que podem ser aplicados aos cursos de graduação nas áreas das engenharias, desde de inserções no ensino básico nas disciplinas de matemática e física, de acordo com a necessidade local da comunidade, sempre objetivando a aproximação do acadêmico com a sociedade, fazendo com que ambos se beneficiem com os projetos (BORGES; CASTRO; LU; OLIVEIRA; RIBEIRO; SILVA, 2012).

\section{$2.1 \quad$ Trabalho voluntário}

O trabalho voluntario está regulamento no Brasil pela Lei 9608/98. Este tipo de trabalho não deve caracterizar relação de emprego, e deve seguir os regulamentos adotados pela entidade ou instituição que receberá o voluntário, dispondo de organização na produção destas atividades. Percebe-se a importância do trabalho voluntario na sociedade por meio de iniciativas de integração social e a criação de um ambiente de cooperação (BARELI; LIMA, 2012)

O trabalho voluntario não só traz benefícios a sociedade, mas também ao voluntário que elabora as atividades de forma organizada e bem gerenciada, isto contribui com o desenvolvimento pessoal e profissional, produzindo novas amizades e a descoberta de novas habilidades (SOUZA, 2008)

\subsection{Trabalho em grupo}

O trabalho em grupo promove desenvolvimento da atuação ativa dos alunos no procedimento de aprendizagem e contribui com a interação social entre os indivíduos. $O$ trabalho em grupo organizado e bem gerenciado dispondo de problemáticas faz o aluno desenvolver um processo de discussão entre os demais integrantes de equipe acerca da problemática abordada na disciplina, com a finalidade de buscar uma solução, isto resulta em um ambiente de estudo que promove um maior contato social mantendo o bem-estar dos estudantes e os aproximando de um ambiente de trabalho (SILVA, 2008).

\section{PROJETOS ELÉTRICOS}

A inclusão de novas tecnologias que utilizam eletricidade para seu funcionamento vem ganhando maior espaço no meio industrial, corporativo e residencial. Com isto, surge a necessidade das adequações das instalações elétricas para suportarem a carga do sistema, ou no caso de instalações mais antigas, a necessidade de renovação da rede elétrica devido estar desgastada em função do tempo. Para isso, faz-se necessário o desenvolvimento de um projeto elétrico atualizado com todas as melhorias que deverão ser implantadas (FREITAS, 2010).

Um projeto elétrico apresenta uma previsão de como ficará a instalação, detalhando todas as partes, como a localização dos pontos de entrega de energia, condutores, dispositivos de manobra, carga de cada circuito, carga total entre outros detalhes (CREDER 2007).

O responsável por fazer o levantamento e o projeto, deverá desenvolvê-los seguindo as normas regulamentadoras (NR's), e as NBR's que descrevem as especificações mínimas para garantir a segurança das partes envolvidas na instalação e para a produção de um projeto de qualidade (CREDER, 2007).

\section{DESCRIÇÃO DO PROJETO}

O projeto de extensão proposto visa a aplicação dos conhecimentos adquiridos em sala de aula aproximando o aluno a um ambiente análogo com o de mercado de trabalho. 
Além de colocar as teorias aprendidas em prática, o projeto tem o intuito de proporcionar ao participante desenvolver novas habilidades, produzir interação dialógica, interdisciplinaridade e interprofissionalidade, impacto e transformação social.

A tabela 1, apresenta as principais atividades e os responsáveis em executá-las ao longo do projeto.

Tabela 1: Especificações de atividades.

\begin{tabular}{|c|c|c|}
\hline \multicolumn{3}{|c|}{ Projeto de Extensão } \\
\hline Entidades parceiras & Instituição SATC & Prefeitura \\
\hline Disponibilidade & Corpo docente e discente & $\begin{array}{c}\text { Escolas com problemas } \\
\text { elétricos e materiais para } \\
\text { produção do trabalho }\end{array}$ \\
\hline \multicolumn{3}{|c|}{ Atividades } \\
\hline $\begin{array}{c}\text { Corpo docente Engenharia Elétrica e } \\
\text { Técnico eletrotécnica }\end{array}$ & $\begin{array}{c}\text { Corpo discente Engenharia } \\
\text { Elétrica }\end{array}$ & $\begin{array}{c}\text { Corpo discente } \\
\text { Técnico eletrotécnica }\end{array}$ \\
\hline produzidos pelos discentes & $\begin{array}{c}\text { Desenvolvimento de pesquisa, } \\
\text { produzir laudo, projeto elétrico e } \\
\text { memorial. Gestão Coordenação } \\
\text { na etapa de passar } \\
\text { conhecimento ao corpo técnico } \\
\text { e na reforma elétrica }\end{array}$ & $\begin{array}{c}\text { Trabalho voluntário na } \\
\text { etapa da reforma elétrica }\end{array}$ \\
\hline \multicolumn{2}{|c|}{ Comunicação e integração com a sociedade no geral. } \\
\hline
\end{tabular}

Fonte: Do autor (2019)

O objetivo principal deste projeto é a adequação das instalações elétricas de escolas do município de Criciúma, executando desde a parte da avaliação da estrutura existente, da atualização do projeto elétrico até a fase de execução. O projeto deve estar adequado as NRs, NBRs e normas da distribuidora de energia local, e então passar pelos supervisores, e ser aprovado para se dar início à execução da obra. O projeto envolve ainda as seguintes disciplinas expostas na tabela 2, aplicadas na produção do trabalho.

Tabela 2: Disciplinas envolvidas.

\begin{tabular}{|c|c|c|}
\hline Curso & Engenharia Elétrica & Técnico Eletrotécnica \\
\hline \multirow{4}{*}{ Disciplinas } & Circuitos Elétricos I & Circuitos Elétricos \\
\cline { 2 - 3 } & Projetos Elétricos & Projetos Elétricos \\
\cline { 2 - 3 } & $\begin{array}{c}\text { Aspectos de Segurança } \\
\text { em Engenharia Elétrica }\end{array}$ & $\begin{array}{c}\text { Segurança e Normas Técnicas } \\
\text { em Eletricidade }\end{array}$ \\
\cline { 2 - 3 } & Materiais e & Instalações Elétricas \\
& equipamentos elétricos & \multicolumn{2}{|c}{} \\
\hline
\end{tabular}

Fonte: Do autor (2019)

O estudo de caso apresentado neste artigo se deu em um projeto de retrofit da instalação elétrica da E.M.E.I.E.F. Santa Rita de Cássia. Para tal feito, elabora-se a coleta de dados no estabelecimento para a produção de uma análise, levantando todos os pontos de carga, os problemas existentes e necessidades de melhorias para cargas futuras.

Como objetivo final, buscou-se o desenvolvimento de um projeto elétrico que representasse toda a instalação elétrica da escola em questão, considerando melhorias com a inclusão de condicionadores de ar, relacionando os materiais necessários para a execução da reforma e a garantia de um ambiente seguro. 


\subsection{Visitas técnicas e laudo}

Foram realizadas algumas visitas técnicas no intuito de conhecer a edificação e elaborou-se um laudo técnico de avaliação, apresentando um levantamento da situação das instalações elétricas da escola municipal de Criciúma, E.M.E.I.E.F. Santa Rita de Cassia. Observou-se irregularidades nos painéis e quadros de distribuição de energia elétrica, apontando soluções técnicas para os problemas elétricos encontrados de acordo com as normas técnicas aplicáveis.

Por conseguinte, produziu-se a análise dos pontos de utilização de energia elétrica, quanto a segurança, estado de conservação, especialmente quanto ao risco de choques elétricos e verificação de anormalidades de todo o conjunto que faz parte das instalações elétricas da referida escola. Para isto, a análise considera desde o ponto de entrega pela concessionária responsável até os quadros de distribuição, pontos de utilização, fiação, eletrodutos e a eficiência da iluminação.

$\mathrm{Na}$ avaliação da situação da instalação elétrica foi observado inúmeras inconformidades, no quesito segurança e eficiência. Dentre as mais críticas estão a entrada de energia, que era antiga em que o disjuntor não fazia a proteção correta dos cabos, e as tomadas com emendas expostas e irregulares podendo ser verificado na figura 1 e 2 .

Figura 1: Tomada irregular no depósito de alimentos

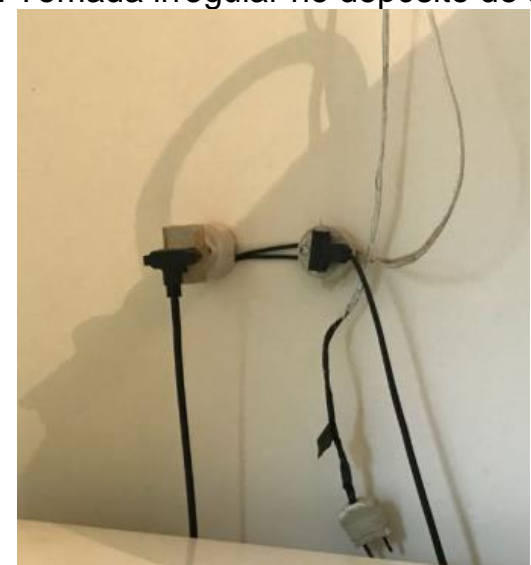

Fonte: Do autor (2018)

Figura 2: Tomada irregular na área de circulação.

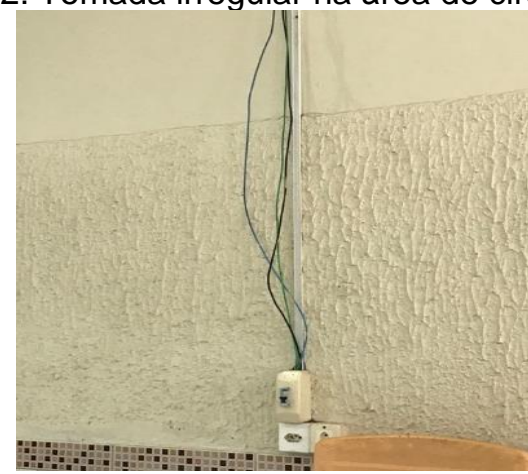

Fonte: Do autor (2018)

A má distribuição e número reduzido das luminárias provocava sombreamento em alguns pontos da sala impossibilitando um iluminamento eficiente para realização da tarefa conforme apresentado na figura 3. 
Figura 3: Verificação visual da iluminação.

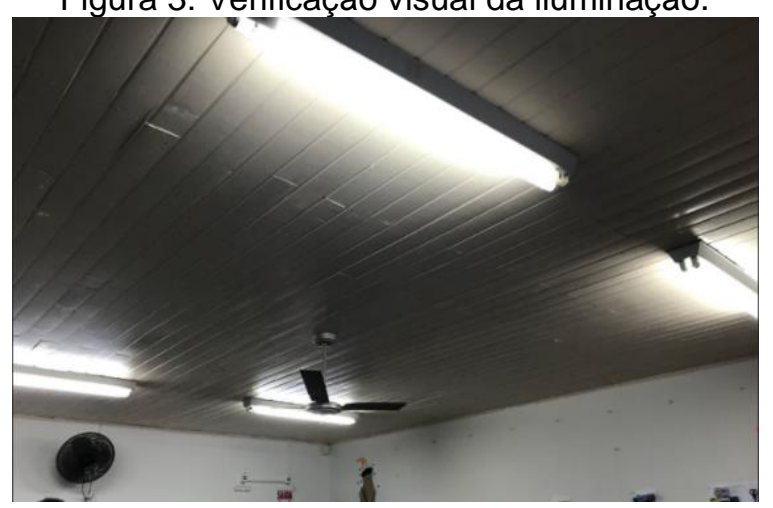

Fonte: Do autor (2018)

\subsection{Projeto Elétrico}

Com o levantamento dos pontos de utilização de energia dispostos na edificação antes da reforma, elaborou-se um projeto elétrico para a correção dos pontos inadequados citados no laudo, inclusão de novas cargas e outras melhorias conforme necessidade, visando atender às normas.

Para os lançamentos dos pontos de entrega de energia se utilizou daqueles que já estavam dispostos na instalação, ou seja, se manteve os pontos, fazendo apenas a inclusão de novos em locais necessários. Dentre os principais pontos destaca-se: tomadas em todas as dependências e para os condicionadores de ar nos seguintes ambientes: refeitório, sala de professores, secretaria, salas de aula, e incluídos também, mais pontos de iluminação nas salas. Para a entrada de energia elaborou-se um novo projeto, apresentando o sistema de aterramento conforme as normas.

Para divisão dos circuitos e dimensionamento de cabos, eletrodutos e dispositivos de proteção, foi seguido rigorosamente a norma NBR 5410 que especifica todos os critérios necessários para a garantia do correto funcionamento da instalação elétrica.

\subsection{Execução do projeto}

Com o projeto aprovado inicia-se a organização para se produzir a reforma elétrica da escola. Para realizar esta tarefa, alunos do curso técnico da instituição têm a possibilidade de poder aprender em campo, fazendo o local de execução como laboratório para a execução das instalações elétricas, além de aplicar o conhecimento teórico aprendido em sala aula e produzir um trabalho voluntário contribuindo com a comunidade local.

Para se ter uma melhor organização e possibilitar um melhor entendimento, produziu-se um cronograma de atividades. Com isto, os acadêmicos responsáveis pelo projeto, planejam dias para a visita e execução do projeto na escola. O tempo estimado para execução deste projeto foi de 15 dias, sendo que o primeiro dia ficou reservado para os acadêmicos de Engenharia Elétrica apresentarem o projeto aos alunos do técnico e visitar o local. Os demais dias ficaram reservados para a execução das atividades.

Além disto foi feito previamente um reconhecimento do local e solicitado a retirada dos alunos (crianças) da área a ser executada a reforma. Para cada atividade eram apresentados os passos corretos a serem seguidos com a objetivo de garantir a segurança e o aprendizado dos alunos participantes, conforme Figura 4. 
Figura 4: Montagem das luminárias novas.

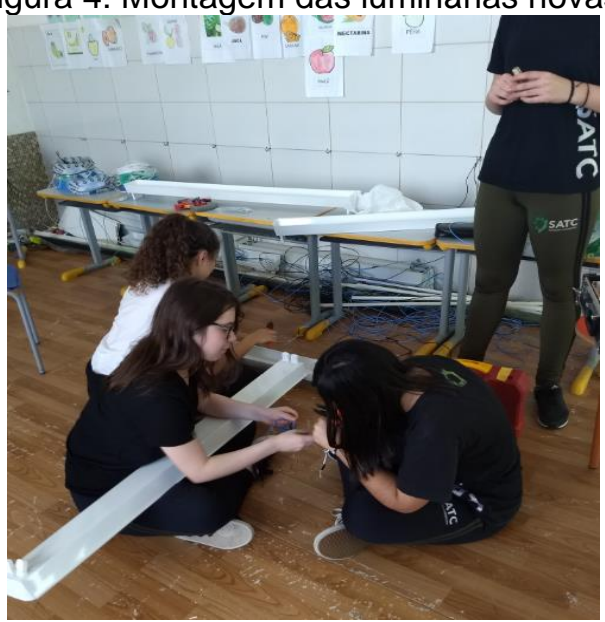

Fonte: Do autor (2018)

Os alunos do curso técnico foram divididos em equipes que se destinavam a tarefas específicas, como por exemplo, uma equipe era responsável pela iluminação, outra pelas tomadas e outra pela passagem da fiação, podendo ser visto nas figuras 5 e 6 .

Figura 5: Execução das tarefas.

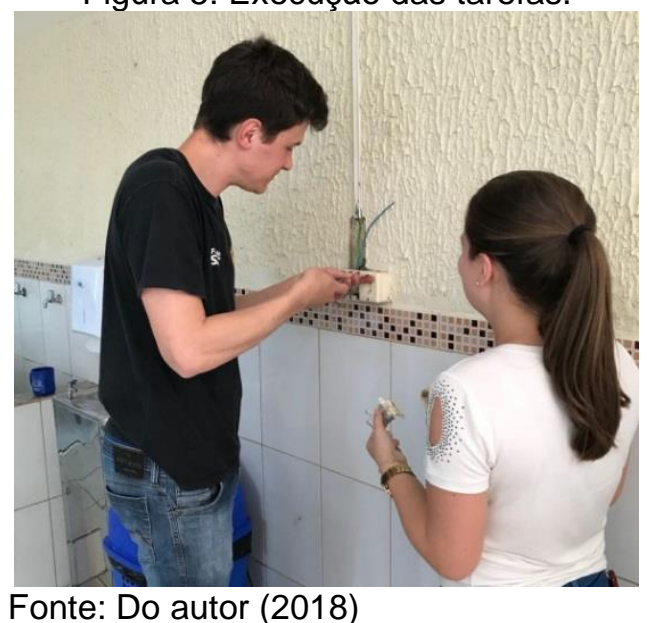

Figura 6: Execução das tarefas.

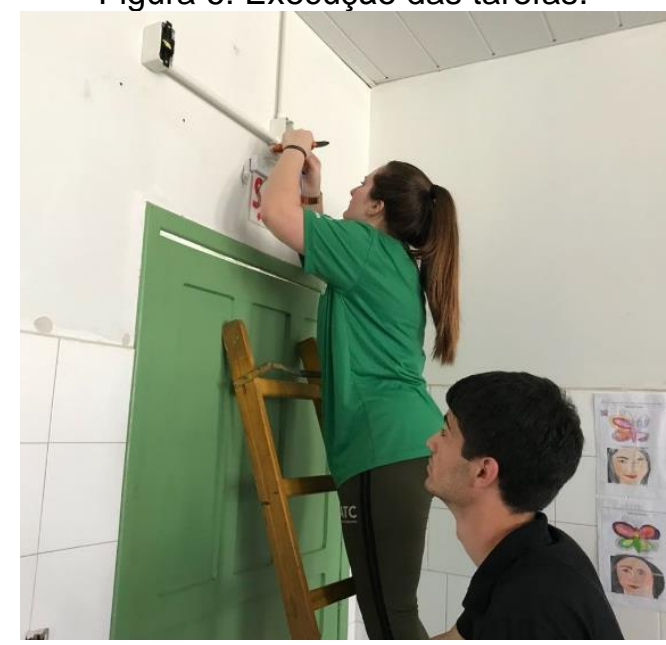

Fonte: Do autor (2018) 
$\mathrm{Na}$ reforma elétrica da escola foram substituídos todos os pontos de entrega de energia por novos, isto inclui tomadas, interruptores, pontos para iluminação, e fiação além da inclusão de novos pontos para colocação de ar condicionado, tomadas e iluminação.

\section{RESULTADOS}

Com a reforma concluída, é possível avaliar os resultados. Assim os professores, acadêmicos do curso de Engenharia Elétrica e alunos do curso técnico compararam o que foi previsto no projeto por meio de uma inspeção à instalação finalizada.

A reforma elétrica foi concluída em 18 dias, porém alguns pontos ficaram a cargo da Prefeitura Municipal de Criciúma como é o caso da entrada de Energia, da inspeção de aterramento e providenciar a adequação do QGBT.

Para garantir o funcionamento da nova instalação, foram realizadas as medições e confirmado o funcionamento de todos os pontos de energia.

De acordo com a norma NBR ISO 8995-1 que específica que a iluminação na área de trabalho de salas de aula deve dispor de um valor intermediário de 300 lux, foram realizadas medições de luminosidade nas salas de aula da escola em questão, e foi medido por meio de um luxímetro. Constatou-se que as salas de aula apresentam iluminação apropriada para as atividades do local após a reforma elétrica conforme a figura 7.

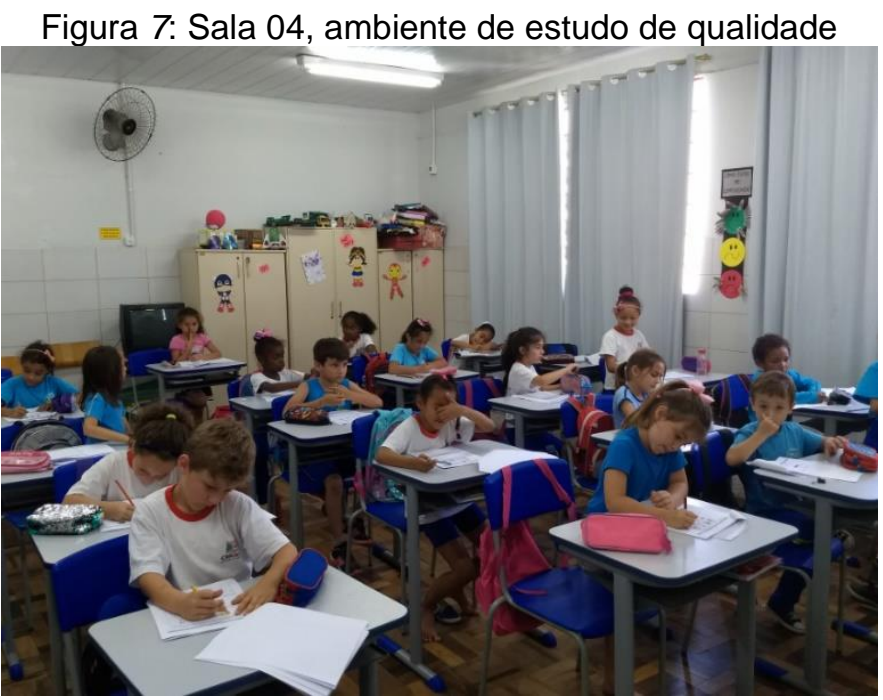

Fonte: Do autor (2018)

Com a reforma concluída, o projeto cumpre com o objetivo de auxiliar a prefeitura municipal de Criciúma na elaboração de reforma elétrica de uma escola pública. Proporcionando aos educadores e educandos maior qualidade no ambiente de estudo.

\subsection{Feedback avaliação dos acadêmicos participantes}

Após a execução da reforma elétrica, os alunos foram questionados sobre os principais fatores que impactaram na sua formação durante a participação deste projeto de extensão.

Dentre os itens em questão os alunos relataram que houve uma melhora significativa no desempenho em sala de aula devido ao projeto, sendo que $76,5 \%$ dos alunos concordaram totalmente e $23,5 \%$ concordaram parcialmente. Ainda, $67,6 \%$ concordaram que o projeto proporcionou o descobrimento de novas habilidades, e $32,4 \%$ concordaram parcialmente. 
Um dos aspectos de um projeto de extensão está ligado a interação dialogada dos alunos, como o programa proporciona o contato entre pessoas de diferentes níveis de ensino e com a comunidade local, faz com que o aluno se torne menos tímido e interaja mais. Conforme a pesquisa realizada, $70,6 \%$ dos alunos concordaram totalmente e $29,4 \%$ concordaram parcialmente que o projeto promoveu a diálogo entre todos e buscou a transformação social.

Participar do programa de extensão contribui significativamente para a potencialização das capacidades particulares, grupais e no desenvolvimento da autoconfiança do discente. O projeto de extensão requer engajamento dos envolvidos, pois, necessita da cooperação de todos e instiga aos alunos a conversarem entre si para tirar dúvidas e organizarem-se da melhor forma.

Para desenvolvimento de um projeto elétrico e a execução de uma reforma elétrica, há a necessidade de planejamento, o projetista necessita locar os pontos de consumo de energia, seguir normas e por fim garantir o correto funcionamento da instalação elétrica. Neste projeto, $73,5 \%$ dos alunos concordaram que o trabalho proporcionou a capacidade de pensar criticamente, e refletir sobre soluções nos problemas encontrados no decorrer da reforma elétrica.

\section{CONSIDERAÇÕES FINAIS}

Uma instalação elétrica precisa passar por revisões e atualizações ao longo dos anos, visto que existe um crescimento na utilização de novos equipamentos e tecnologias que necessitam da eletricidade. Essas tecnologias fazem com que a demanda de energia aumente, solicitando mais energia das instalações e redes elétricas fazendo com que fiquem desatualizadas. Por isto, é de suma importância que se faça as devidas correções na rede para o recebimento de novos equipamentos, garantindo a segurança dos usuários, evitando o mau funcionamento e acidentes causados por choques ou incêndios devido às sobrecargas no sistema.

Um projeto de extensão aproxima o aluno da sociedade e assim consegue contribuir tanto na formação dos estudantes como também na melhoria da comunidade em que 0 projeto está inserido, gerando benefícios para ambos os lados.

O presente trabalho faz referência ao projeto de extensão "Energize sua Escola" que visa avaliar a situação da rede elétrica das escolas, executando se necessário o projeto elétrico e a reforma elétrica da mesma. O projeto foi realizado pelos alunos dos cursos de Engenharia Elétrica e Técnico em Eletrotécnica da SATC e proporcionou as melhorias necessárias nas instalações elétricas da escola E.M.E.I.E.F. Santa Rita de Cássia, beneficiando 104 alunos e 11 professores.

Além da satisfação dos resultados pela sociedade, os alunos participantes demonstraram em sua maioria que o projeto contribuiu para o seu desenvolvimento acadêmico. Sendo assim, o programa de extensão traz benefícios não só para a universidade e alunos, mas também a comunidade em geral.

\section{REFERÊNCIAS}

ANDRADE, T. H. N; INCROCCI, L. M. M. C. O fortalecimento da extensão no campo científico: uma análise dos editais ProExt/MEC. Revista Sociedade e Estado, v. 33, n. 1, p.189-214, 2018. 
ARAÚJO FILHO, T.; THIOLLENT, M. J. Metodologia para Projetos de Extensão: Apresentação e Discussão. São Carlos: Universidade Federal de São Carlos. Cubo Multimídia, 2008. 666 p.

BORGES, A. M.; CASTRO, R. N. A.; LU, Y. L.; OLIVEIRA, A. G.; RIBEIRO, C. J.; C.; SILVA, A. G. Atividades de Extensão na Formação do Engenheiro: A Experiência da UFG. COBENGE - XL Congresso Brasileiro de Educação em Engenharia. 2012.

CARBONARI, M. E. E.; PEREIRA, A. C. A extensão universitária no Brasil, do assistencialismo à sustentabilidade. Revista de Educação, v. 10, n. 10, p.23-28, 2007.

CREDER, H. Instalações Elétricas. 15. ed. Rio de Janeiro: Livros Técnicos e científicos, 2007.

FREITAS, Luciana. Renovando as instalações. Lumière, São Paulo, v. 12, n.149, p. 3642, set.2010.

BARELI, P.; LIMA, A. J. F. S. A importância social do desenvolvimento do trabalho voluntário. Disponível em:

http://www.eticaempresarial.com.br/imagens_arquivos/artigos/File/Monografias/artigo _voluntariado.pdf >. Acesso em: 03 out. 2019.

SILVA J. A. P. O uso de dinâmicas de grupo em sala de aula. Um instrumento de aprendizagem experiencial esquecido ou ainda incompreendido? Saber Científico, Porto Velho, 1 (2): 82- 99, julho/dezembro, 2008.

SOUZA, S. A. Educação, trabalho voluntário e responsabilidade social da empresa: "amigos da escola" e outras formas de participação. 2008. Tese (Doutorado em Educação) - Faculdade de Educação, Universidade de São Paulo, São Paulo, 2008. Disponível em: < http://www.teses.usp.br/teses/disponiveis/48/48134/tde-16062008103840/publico/Tese.pdf>. Acesso em: 03 out. 2019.

\section{ENERGIZE YOUR SCHOOL: AN EXTENSION PROJECT THAT UNITES DIFFERENT LEVELS OF EDUCATION}

Abstract: Extension projects, when properly developed, make a huge impact on society and on the formation of students and teachers who work in it. This article presents phases of development, and the main results obtained in the social and academic field of the project entitled "Energize your School". A unique feature of this project is the interaction between the different levels of education, in being this, electrical engineering academics and students of the Electrotechnical course at the SATC teaching institution. Also presents the relation between the subjects of the course and what is developed in this extension project. Lastly, feedback is presented from the perspective of the students who participated in this project of the municipal school of Criciúma, E. M. E. I. E. F Santa Rita de Cássia in the year 2018.

Keywords: Education, Extension, Social Work, Electricity. 